\title{
Bevacizumab in combination with chemotherapy in the first-line treatment of metastatic colorectal carcinoma
}

\author{
V. USAKOVA ${ }^{1, *}$, K. SEVCIKOVA ${ }^{1,2}$, J. USAK ${ }^{3}$, Z. BARTOSOVA ${ }^{4}$, M. MIKULOVA ${ }^{1}$, S. SPANIK ${ }^{1,2}$ \\ ${ }^{1}$ Department of Medical Oncology, St. Elizabeth Cancer Institute, Bratislava, Slovak Republic; ${ }^{2} 1$ st Department of Oncology, Comenius University, \\ Faculty of Medicine, St. Elizabeth Cancer Institute, Bratislava, Slovak Republic; ${ }^{3}$ Department of Internal Medicine, Faculty Hospital Trnava, \\ Slovak Republic; ${ }^{4}$ Department of Clinical Genetics, St. Elizabeth Cancer Institute, Bratislava, Slovak Republic
}

*Correspondence: vanda.usakova@gmail.com

Received January 30, 2012 / Accepted August 3, 2012

\begin{abstract}
Colorectal carcinoma (CRC) is a malignancy of worldwide increased incidence. The vast majority of all CRC cases occur in patients older than age 50. The initial stage at the time of diagnosis has a strong influence on the overall survival (OS). According to AJCC sixth edition system, 5-year stage-specific survivals are over $90 \%$ in stage I, but only approximately $8 \%$ in stage IV [1]. Chemotherapy in combination with biological treatment has improved response rates (RR), with prolongation of progression free survival (PFS) and OS. Important role in treatment of metastatic colorectal carcinoma (mCRC) plays surgical resection of metastases. Multidisciplinary cooperation between medical oncologist, surgeon, radiologist and radiotherapist is necessary to achieve the best therapeutic results. The aim of our analysis was to describe the efficacy of bevacizumab used in combination with chemotherapy in the first-line setting and to evaluate frequency of thromboembolic complications during the treatment. The analysis included 58 patients with mCRC, who have been treated with first-line chemotherapy in combination with bevacizumab at the St. Elizabeth Cancer Institute in Bratislava since 2006 and first assessed for the first therapeutic results in October 2010. The clinical benefit after the treatment represented by overall response rate (ORR) and stable disease (SD) was achieved in $87.93 \%$ of patients, and surgical resection of metastases after therapy underwent $12.07 \%$ of patients. Median time to progression (TTP) was 8 months and median OS evaluated in October 2011 was 27 months. Mutation status of KRAS gene had no influence on the effectiveness of treatment and BRAF mutations exhibited a strong negative prognostic significance. Thromboembolic complications were present in $17.24 \%$.
\end{abstract}

Key words: metastatic colorectal carcinoma, first-line treatment, biological treatment, molecular markers, bevacizumabrelated toxicity

Colorectal carcinoma is one of the leading causes of death from cancer worldwide [2]. Interestingly, the localization of primary tumor varies depending on age. Some studies revealed, that young patients $(<40)$ tend to develop rightsided colon tumors, whereas the tumors in patients $>40$ are more often localized in the left colon [3]. The incidence and mortality rates are slightly higher in men than in women. The most frequent localizations for metastatic spread are liver and lung. Approximately one quarter of CRC patients present with distant metastases at initial diagnosis, and almost 50\% will develop them later, which has a strong influence on overall prognosis [4]. Only radical surgery offers the chance of longterm survival. After complete resection of single metastasis, the 5-year survival may exceed 50\%, and in case of less than four lesions, the 5-year survival reaches $30-50 \%[5,6]$. In certain cases of initially unresectable disease, the metastases can become suitable for resection throughout a so-called conversion therapy.

For more than 40 years the only drug available for $\mathrm{mCRC}$ was 5-fluorouracil (5-FU), the use of which gives RR of 10$15 \%$ and median survival of 10 months. Important change in treatment of mCRC brought the addition of new cytostatics (irinotecan and oxaliplatin) and several studies confirmed that it is possible to achieve higher RR (40-50\%), PFS (7-9 months) and OS (16-20 months) with combined regimens $[7,8,9]$. Another important progress in treatment of $\mathrm{mCRC}$ represents targeted biological therapy using monoclonal antibodies - anti-VEGF (bevacizumab) and anti-EGFR (cetuximab, panitumumab). Combined cytostatic therapy together with targeted biological treatment and improved 


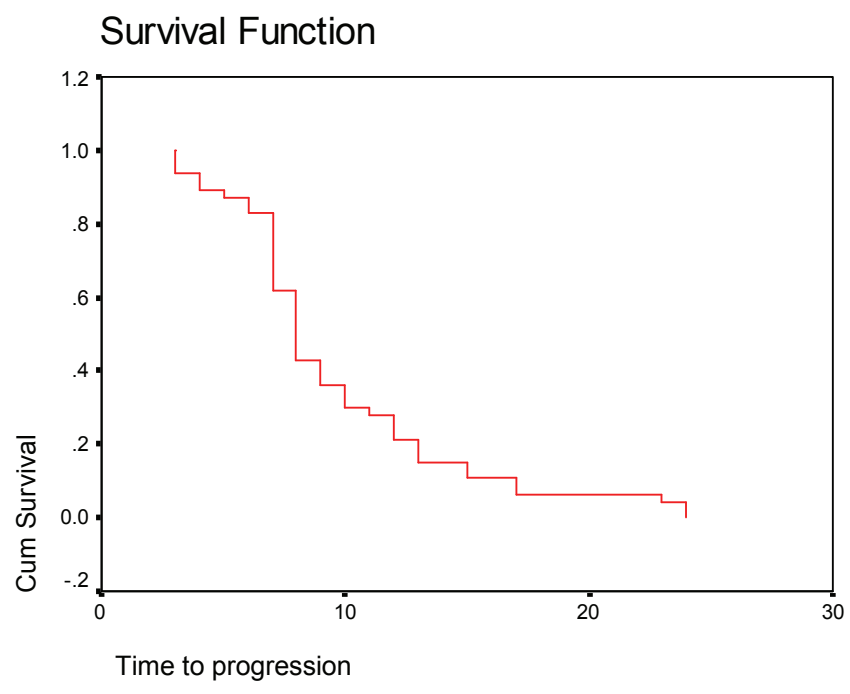

Figure 1. Kaplan-Meier analysis of TTP in 58 patients with mCRC. Median TTP was 8 months.

techniques to resect metastatic disease have improved the median survival of patients with mCRC from 6 months to 2 years. Treatment strategy depends on the treatment aim. Aggressive approach is indicated in patients with potentially resectable metastases, with symptomatic disease in whom tumor regression is needed and in patients with the risk of rapid deterioration due to the aggressive tumor biology and/or extensive disease. In patients with clearly unresectable disease, without tumor-related symptoms and low risk of rapid progression as well as comorbidity, a sequential therapy starting with a fluoropyrimidine monotherapy in combination with biological agent bevacizumab is the valid option.

Before starting the treatment by biological agent, the assessment of relevant predictive and prognostic molecular markers may be of interest. While prognostic markers identify patients with different outcome of the disease regardless of treatment strategy, predictive marker helps us to predict efficiency of a particular therapy [10]. The most important predictive marker for anti-EGFR therapy is KRAS mutational status. Many retrospective and prospective studies have shown, that KRAS mutations that occur approximately in $40 \%$ of patients with CRC are associated with resistance to anti-EGFR antibodies cetuximab and panitumumab [11-17]. This resistance is presented when anti-EGFR antibodies are used as a single agent or in combination with chemotherapy, in pretreated patients as well as in early lines of treatment. However, only $40-60 \%$ of $K R A S$ wild-type patients respond to treatment suggesting that other molecular markers have to be considered in the future. One of them is $B R A F$ gene that may be mutated up to $6-10 \%$ of patients with $\mathrm{mCRC}[18,19]$. Interestingly, $B R A F$ and KRAS mutations are mutually exclusive. Several studies have confirmed, that presence of the BRAF mutation corre-

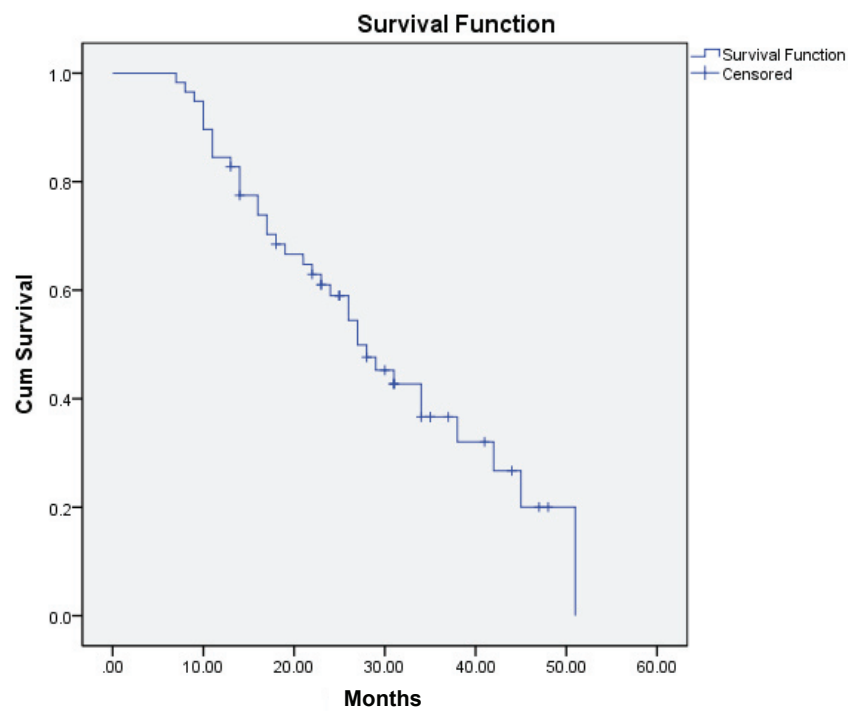

Figure 2. Kaplan-Meier analysis of OS in 58 patients with mCRC. Median survival was 27 months.

lates with resistance to anti-EGFR therapy in chemorefractory mCRC [19-22]. However the available data on the strength of $B R A F$ status for predicting response to anti-EGFR therapy are limited by retrospective analyses and small numbers of evaluated patients. Moreover, updated data from CRYSTAL study suggest that $K R A S$ wild-type/BRAF mutant patients may actually respond to anti-EGFR therapy [18]. On the other hand, many studies have confirmed, that $B R A F$ is a poor prognostic marker, because patients with this mutation have shorter PFS and OS, regardless of the type of treatment $[18,19,23]$.

Anti-VEGF therapy is represented by monoclonal antibody bevacizumab. Bevacizumab is a recombinant humanized monoclonal IgG antibody that specifically binds all isotypes of VEGF-A. VEGF-A is a member of the VEGF platelet-derived growth factor gene family and represents one of the most potent positive regulators of angiogenesis, including tumor angiogenesis. Its biological effects are mediated by binding to two tyrosine kinase receptors (VEGFR-1 and VEGFR-2) [24]. Since angiogenesis is essential for the growth, progression and metastasis of solid tumors, both VEGF-A and its receptors have been evaluated as potential therapeutic targets.

The problem with bevacizumab is that there are currently no clear predictive molecular markers for anti-VEGF therapy. According to the so far published studies, the presence of KRAS mutation does not seem to influence the outcome of anti-VEGF therapy probably because VEGF and RAS signalling pathways are independent of each other.

The toxicity of anti-VEGF and anti-EGFR therapy is different. Most frequent toxicity associated with cetuximab is acne-like rash. The freqeuency of acne-like rash in large, phase III studies of cetuximab in mCRC was $78-88 \%$, with most events of grade 1 or 2 intensity [25]. Other adverse effects include infusion reactions and electrolyte dysbalances. Toxic- 
ity profile of bevacizumab was assessed in several prospective randomised clinical trials as well as in observational studies [26-30]. Most adverse events associated with bevacizumab (hypertension, proteinuria and bleeding) are mild-moderate in severity and are manageable using standard therapies [26,31-33]. To more serious adverse events reported with bevacizumab belong thromboembolic events, gastrointestinal (GI) perforations and wound-healing complications. But serious toxic effects related to bevacizumab have generally the incidence of $<5 \%$ [34].

The aim of our study was to perform a descriptive, retrospective analysis of patients with $\mathrm{mCRC}$ treated with chemotherapy and bevacizumab in the first line.

\section{Patients and methods}

Our analysis included 58 patients $>18$ years old with histologically confirmed mCRC who were treated with first-line fluoropyrimidine-based chemotherapy in combination with bevacizumab from January 2006. The first part of results was assessed in October 2010, OS was evaluated in October 2011. The chemotherapy regimens contained single agent fluoropyrimidine or fluoropyrimidine plus irinotecan (regimens IFL - irinotecan, 5-fluorouracil bolus injection, leucovorin (LV); XELIRI - irinotecan, capecitabine; FOLFIRI - irinotecan, 5FU continuous infusion, LV) or oxaliplatin (regimens XELOX - oxaliplatin, capecitabine; FOLFOX 4 - oxaliplatin, 5-FU continuous infusion, LV). Bevacizumab dose was $5 \mathrm{mg} / \mathrm{kg}$ every 2 weeks or $7.5 \mathrm{mg} / \mathrm{kg}$ every 3 weeks. Bevacizumab was administered i.v., initially over $90 \mathrm{~min}$. If the first infusion was well tolerated, the second was delivered over $60 \mathrm{~min}$; if the $60 \mathrm{~min}$ infusion was well tolerated, all subsequent infusions were delivered over $30 \mathrm{~min}$. Bevacizumab doses were not reduced or escalated; in cases of serious bevacizumab-related toxicity, drug was temporarily or permanently suspended. The analysis included also those patients who underwent adjuvant treatment for colorectal cancer in the past. The aim of our study was to evaluate following parameters in the cohort: age structure and gender of patients, localization of primary tumor and metastases, resectability of metastases, RR, OS, TTP and frequency of thromboembolic events during the treatment. We have also assessed genetic profile of the patients - frequency of KRAS and BRAF mutations in the tumor and importance of $B R A F$ as a negative prognostic factor. We didn't performed VEGF staining because it is not demanded to check it before starting the treatment of $\mathrm{mCRC}$ with bevacizumab and it is not being evaluated in our institute.

RR were evaluated according to RECIST criteria [35] and the used imaging modality was computed tomograhpy (CT). As a complete response (CR) we considered disappearance of all target lesions and each pathological lymph node had to have a short axis reduction to $<10 \mathrm{~mm}$. Partial response was defined as at least $30 \%$ decrease in the sum of diameters of target lesions, taking the baseline sum diameters as a reference value. Progressive disease (PD) was defined as at least $20 \%$ increase in the sum of diameters of target lesions, taking the smallest sum as a reference value and the sum must also demonstrate an absolute increase of at least $5 \mathrm{~mm}$. In case that the response was not PR neither PD we have assigned it as a SD. All patients were monitored equally and we have not offered any investigations above the framework of routine clinical practice. TTP and OS were calculated using KaplanMeier analysis.

KRAS and BRAF mutational analysis. The most common $K R A S$ and $B R A F$ point mutations were identified by focusing our analysis on exons 2 and 15, respectively (exon 2 includes codons 12 and 13 of KRAS, and exon 15 included codon 600 of $B R A F$, which represent the mutational hot spots leading to gain-of-function mutations in the respective proteins). KRAS exon 2 was PCR-amplified from tumor DNA as a $173 \mathrm{bps}$ fragment, whereas exon 15 of BRAF was PCR-amplified as $103 \mathrm{bps}$ fragment. PCR products were purified by ExoSAP-IT ${ }^{\circ}$ kit (USB Corporation, Cleveland, Ohio) at $37^{\circ} \mathrm{C}$ for $45 \mathrm{~min}$ and subsequently at $80^{\circ} \mathrm{C}$ for $15 \mathrm{~min}$. Mutations were then assessed by ABI PRISM SNaPshot Multiplex Kit (Applied Biosystems, Foster City, CA, USA) at the relevant nucleotides using single base extension $\mathrm{SNaPshot} \mathrm{primers} \mathrm{(the} \mathrm{sequences}$ are available on request). The multiplex $\mathrm{SNaPshot} \mathrm{reaction} \mathrm{was}$ performed in a final volume of $10 \mu \mathrm{l}$, containing $1 \mu \mathrm{l}$ of each PCR product, $2 \mu \mathrm{l}$ of the $\mathrm{SNaPshot}$ Multiplex Ready Reaction Mix, $1 \mu \mathrm{l}$ of $5 \mathrm{x}$ sequencing buffer of Big Dye V3.1 Terminator Kit and SNaPshot primers at 0.01-0.06 $\mu \mathrm{M}$ concentration. Cycling conditions were carried out according to the manufacturer's kit recommendation and $\mathrm{SNaPshot} \mathrm{products} \mathrm{were}$ subsequently purified by treatment with $2 \mathrm{U}$ of shrimp alkaline phosphatase (USB Corporation, Cleveland, Ohio) at $37^{\circ} \mathrm{C}$ for $45 \mathrm{~min}$. After heat inactivation of the enzyme at $80^{\circ} \mathrm{C}$ for $15 \mathrm{~min}$, the fluorescently labeled products were separated using a 7 min run on ABI Prism 3130 DNA sequencer and data were analyzed using GeneMapper Analysis Software version (Applied Biosystems).

\section{Results}

Our analysis included 58 patients with median age 55.65 years, CRC was more often diagnosed in men $(n=34)$ than in women $(n=24)$. The median age was 57.53 in men and 55.17 in women. Primary tumor was more frequently localized in the left colon and typical localization of metastatic spread was the liver (Table 1).

Twenty-five patients $(43,10 \%)$ underwent adjuvant chemotherapy for CRC in the past. Bevacizumab was used in first-line

Table 1. Localization of metastases

\begin{tabular}{lccc}
\hline Metastases & Total & Men & Women \\
\hline Peritoneum & $10(17,24 \%)$ & 5 & 5 \\
Liver & $28(48,27 \%)$ & 15 & 13 \\
Lungs & $8(13,79 \%)$ & 5 & 3 \\
Multiorgan & $12(20,68 \%)$ & 9 & 3 \\
\hline
\end{tabular}


Table 2.1 Used chemotherapy regimens

\begin{tabular}{|c|c|}
\hline Name of Regimen & Schedule \\
\hline XELOX & Oral capecitabine $\left(1000 \mathrm{mg} / \mathrm{m}^{2}\right)$ twice a day for 14 days plus oxaliplatin $\left(130 \mathrm{mg} / \mathrm{m}^{2}\right)$ on day 1 every 3 weeks \\
\hline FOLFOX 4 & $\begin{array}{l}\text { Oxaliplatin }\left(85 \mathrm{mg} / \mathrm{m}^{2}\right) \text { administered as a } 2 \text {-hour infusion on day } 1 \text {; leucovorin }\left(200 \mathrm{mg} / \mathrm{m}^{2}\right) \text { administered as a 2-hour infusion } \\
\text { on day } 1 \text { and day 2; followed by a loading dose of 5-FU }\left(400 \mathrm{mg} / \mathrm{m}^{2}\right) \text { IV bolus, then } 5 \text {-FU }\left(600 \mathrm{mg} / \mathrm{m}^{2}\right) \text { administered via pump } \\
\text { for a period of } 22 \text { hours on day } 1 \text { and day } 2 \text {, every } 2 \text { weeks }\end{array}$ \\
\hline IFL & $\begin{array}{l}\text { Irinotecan }\left(100-125 \mathrm{mg} / \mathrm{m}^{2}\right), 5-\mathrm{FU}\left(425-500 \mathrm{mg} / \mathrm{m}^{2}\right) \text { IV bolus, and leucovorin }\left(20 \mathrm{mg} / \mathrm{m}^{2}\right) \text { IV bolus administered weekly for } \\
4 \text { out of } 6 \text { weeks }\end{array}$ \\
\hline XELIRI & Irinotecan $\left(200 \mathrm{mg} / \mathrm{m}^{2}\right)$ administred on day one and capecitabine $\left(800 \mathrm{mg} / \mathrm{m}^{2}\right)$ twice a day for 14 days $2-15$, every 21 days \\
\hline FOLFIRI & $\begin{array}{l}\text { Irinotecan }\left(180 \mathrm{mg} / \mathrm{m}^{2}\right) \text { administered as a } 2 \text {-hour infusion on day } 1 \text { only; leucovorin }\left(200 \mathrm{mg} / \mathrm{m}^{2}\right) \text { administered as a } 2 \text {-hour } \\
\text { infusion on days } 1,2 ; 5 \text {-FU }\left(400 \mathrm{mg} / \mathrm{m}^{2}\right) \text { IV bolus administered on day } 1 \text { and day } 2,5 \text {-FU }\left(600 \mathrm{mg} / \mathrm{m}^{2}\right) \text { administered via pump } \\
\text { for a period of } 22 \text { hours on day } 1 \text { and day } 2 \text {, every } 2 \text { weeks }\end{array}$ \\
\hline Fluoropyrimidine alone & capecitabine $\left(1250 \mathrm{mg} / \mathrm{m}^{2}\right)$ twice a day for 14 days, every 21 days \\
\hline
\end{tabular}

Table 2.2 Chemotherapy regimens in combination with bevacizumab and TTP

\begin{tabular}{llcccc}
\hline Chemotherapy (+ bevacizumab) & & Men & Women & Total & Time to progression \\
\hline $\begin{array}{llll}\text { Oxaliplatin-based } \\
\text { regimens }\end{array}$ & XELOX & 6 & 4 & 15 & 8,7 \\
\hline Irinotecan-based regimens & FOLFOX 4 & 2 & 3 & 14 & 42 \\
& IFL & 16 & 6 & 10 \\
& XELIRI & 6 & - & 1 & 7 \\
\hline Other & FOLFIRI & 4 & 1 & & \\
\hline
\end{tabular}

in combination with chemotherapy. Exact schedules of used chemotherapy regimens are described in Table 2.1. Irinotecan-based regimens (IFL, FOLFIRI, XELIRI) were used more frequently than oxaliplatin-based regimens (XELOX, FOLFOX 4) while fluoropyrimidine as a single agent was used only in one case (Table 2.2).

Clinical benefit represented by ORR (CR and PR) plus SD was achieved in 51 patients $(87.93 \%)$. The rest of the patients have experienced PD after treatment. CR was achieved in

Table 3. Objective tumor response rates

\begin{tabular}{llccc}
\hline Therapeutic effect & Type of response & Total & Men & Women \\
\hline Clinical benefit & Total & $51(87,93 \%)$ & 30 & 21 \\
& Complete response & $6(11,76 \%)$ & 4 & 2 \\
& Partial response & $13(25,49 \%)$ & 6 & 7 \\
& Stable disease & $32(62,75 \%)$ & 20 & 12 \\
\hline Progressive disease & & $7(12,06 \%)$ & 4 & 3 \\
\hline
\end{tabular}

Table 4. Resection of metastases

\begin{tabular}{lcc}
\hline \multicolumn{3}{c}{ Resection achieved with treatment } \\
\hline Liver & Other (lungs) \\
\hline Men $(\mathbf{n}=34)$ & 3 & 0 \\
Women $(\mathrm{n}=24)$ & 3 & 1 \\
Total $(\mathrm{n}=58)$ & $6(10,34 \%)$ & $1(1,72 \%)$ \\
\hline
\end{tabular}

6 patients (11.76\%), PR in 13 patients (25.49\%) and SD in 32 patients $(62.75 \%)$.

Twenty-two patients underwent resection of metastases and 7 of them achieved operability of metastases after the treatment with chemotherapy in combination with bevacizumab, here of 6 patients had liver and 1 patient had lung metastases. The data about response rates and resection of metastases are summarized in Table 3 and Table 4. OS in patients who underwent resection of metastates are shown on Figure 3.

Median TTP in patients treated with the first-line chemotherapy in combination with bevacizumab was 8 months as shown on Figure 1 and in Table 5 and was longer in patients treated with irinotecan-based regimens (Table 2.2). Median OS was evaluated in October 2011 and achieved 27 months as demonstrated on Figure 2 and in Table 6. OS according to used chemotherapy regimen and BRAF status are displayed on Figure 4 and 5.

Thromboembolic complications were observed in $10 \mathrm{pa}$ tients (17.24\%). Most frequent complication was a deep thrombophlebitis which was observed in 7 patients. Pulmonary embolism was present in 3 patients and in these cases bevacizumab was permanently suspended.

We have not seen any postoperative complications (bleeding or wound-healing complications) in 7 patients who underwent surgical resection. This was probably reached by preservation of the right time interval (surgery at least 6 weeks after the last applicated dose of bevacizumab).

Majority of tumor samples of the patients enrolled in the study could be analyzed for the presence of KRAS and 


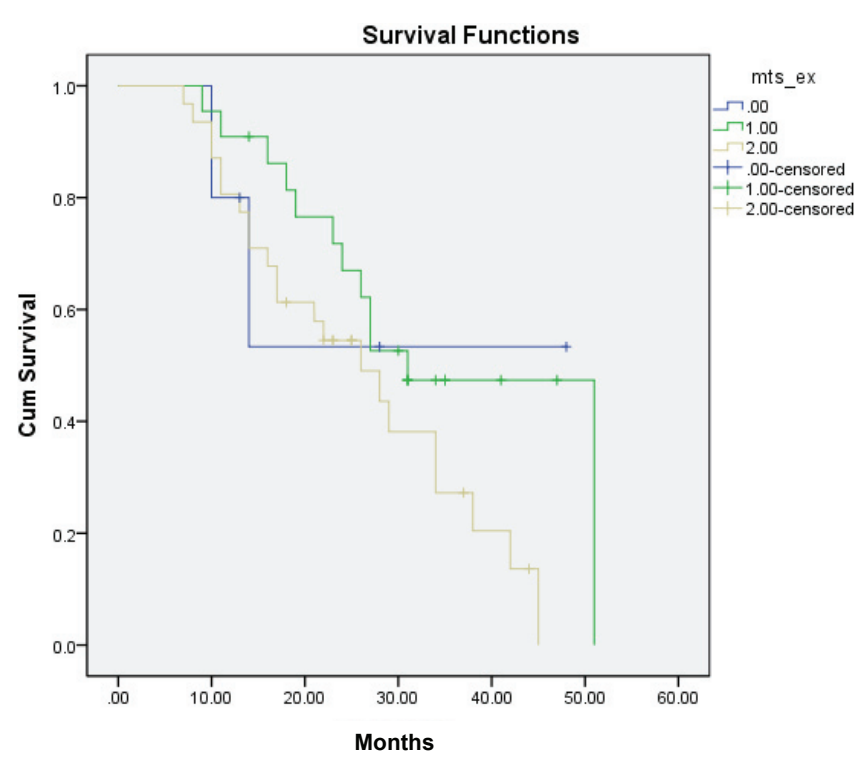

Figure 3. OS in $\mathrm{mCRC}$ patients who underwent resection of metastases as initial treatment $(0)$, after bevacizumab treatment $(1)$ and patients who did not have metastases resection (2).

$B R A F$ mutations. The data from these analyses together with results from EGFR immunohistochemical staining are summarized in Table 7 . The presence of KRAS mutation was confirmed in 22 out of 56 patients (39.29\%) and $B R A F$ mutation was detected in other 3 out of 47 analysed patients $(6.38 \%)$.

We have found that the presence of KRAS mutations had not influenced the response to treatment. However, slightly more than would be expected, (6 out of 7) patients who had progression on chemotherapy in combination with bevacizumab were KRAS wild-type. In the groups of patients with CR, $\mathrm{PR}$ or $\mathrm{SD}$, the cases with or without KRAS mutation occured with similar ratio (data not shown). All patients with $B R A F$ mutations have fallen into PD group.

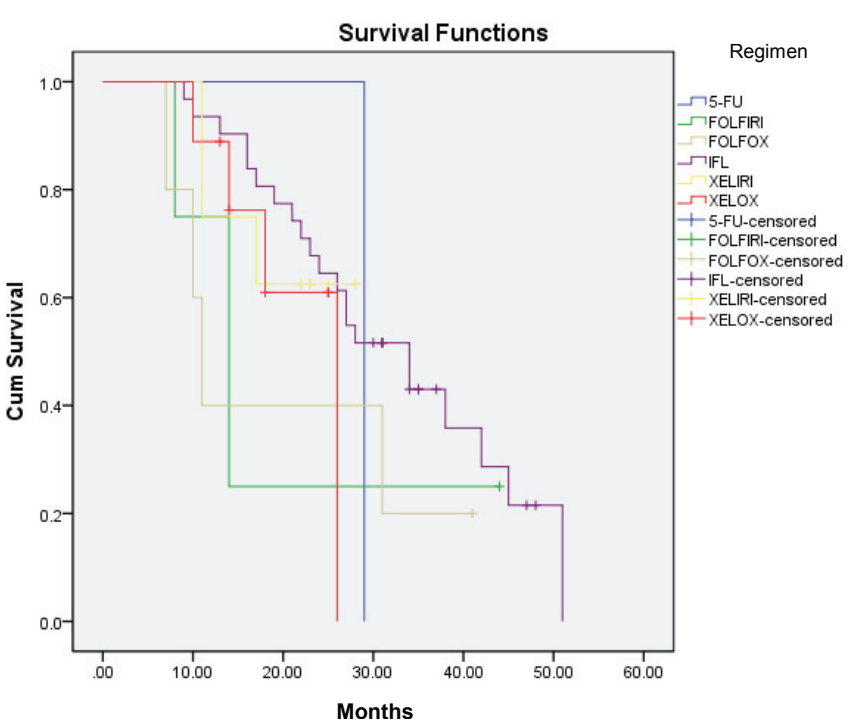

Figure 4. OS in mCRC patients on different chemotherapy regimens.

\section{Discussion}

The purpose of our retrospective analysis was to evaluate the efficacy and safety of bevacizumab when added to firstline cytostatic chemotherapy in patients with histologically confirmed mCRC. We compared the results of our analysis with data from large well-known multicentric studies.

Bevacizumab was used in our analysis in combination with fluoropyrimidine alone or with fluoropyrimidine combined with either oxaliplatin (regimens XELOX, FOLFOX 4) or irinotecan (regimens IFL, XELIRI, FOLFIRI ).

The phase III trial AVF2107g, which compared first-line IFL regimen with and without bevacizumab in patients with $\mathrm{mCRC}$ revealed, that OS and PFS were longer in the IFL-be-

Table 5. Means and medians for time to progression

\begin{tabular}{|c|c|c|c|c|c|c|c|}
\hline \multicolumn{4}{|c|}{ Mean } & \multicolumn{4}{|c|}{ Median } \\
\hline \multirow{2}{*}{ Estimate } & \multirow{2}{*}{ Std. Error } & \multicolumn{2}{|c|}{ 95\% Confidence Interval } & \multirow{2}{*}{ Estimate } & \multirow{2}{*}{ Std. Error } & \multicolumn{2}{|c|}{ 95\% Confidence Interval } \\
\hline & & Lower Bound & Upper Bound & & & Lower Bound & Upper Bound \\
\hline 9.66 & 0.73 & 8.23 & 11.09 & 8.00 & 0.38 & 7.26 & 8.74 \\
\hline
\end{tabular}

Table 6. Means and medians for survival time

\begin{tabular}{|c|c|c|c|c|c|c|c|}
\hline \multicolumn{4}{|c|}{ Mean $^{\mathrm{a}}$} & \multicolumn{4}{|c|}{ Median } \\
\hline \multirow[b]{2}{*}{ Estimate } & \multirow[b]{2}{*}{ Std. Error } & \multicolumn{2}{|c|}{ 95\% Confidence Interval } & \multirow[b]{2}{*}{ Estimate } & \multirow[b]{2}{*}{ Std. Error } & \multicolumn{2}{|c|}{ 95\% Confidence Interval } \\
\hline & & Lower Bound & Upper Bound & & & Lower Bound & Upper Bound \\
\hline 29.843 & 2.159 & 25.611 & 34.074 & 27.000 & 3.010 & 21.100 & 32.900 \\
\hline
\end{tabular}

a. Estimation is limited to the largest survival time if it is censored. 


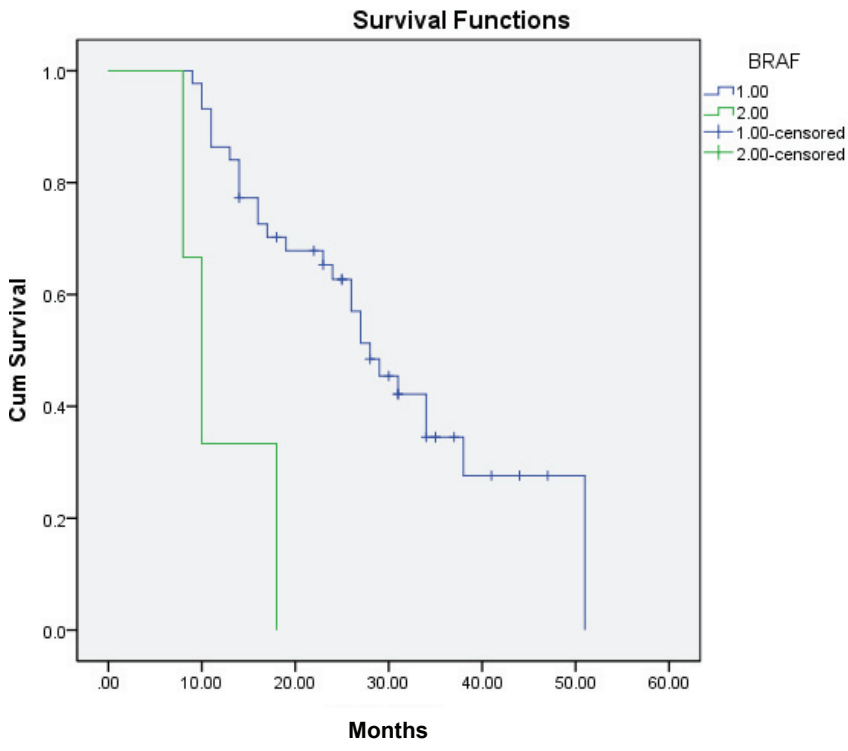

Figure 5. OS in mCRC patients with wild-type (1) and mutated (2) form of BRAF gene.

vacizumab arm [26]. These results led to the initial approval of bevacizumab by the FDA. The phase III BICC-C clinical trial evaluated bevacizumab in combination with regimen FOLFIRI and IFL. The results revealed that the patients in the FOLFIRI-bevacizumab arm had a longer median OS time than those in the IFL-bevacizumab arm and therefore FOLFIRI has gradually replaced IFL $[36,37]$. Another possibility, largely used especially in Europe is regimen XELIRI.

The efficacy of bevacizumab combined with a fluoropyrimidine and oxaliplatin has been evaluated in several randomized trials $[28,33]$. In the phase III NO16966 study [33] the addition of bevacizumab to chemotherapy (regimen XELOX and FOLFOX 4) resulted in a longer median OS time, 21.3 months versus 19.9 months in comparison to chemotherapy-placebo arm, but this difference was not statistically significant $(\mathrm{p}=0.077)$. The response rates were similar but there was a statistically significant longer median PFS interval for

Table 7. Genetic profile of patients

\begin{tabular}{llccc}
\hline & & Men & Women & Total \\
\hline EGFR & Present & 24 & 20 & 44 \\
& Absent & 7 & 4 & 11 \\
& Uninvestigated & 3 & 0 & 3 \\
\hline \multirow{2}{*}{ RRAS } & Wild-type & 21 & 13 & 34 \\
& Mutated & 12 & 10 & 22 \\
& Uninvestigated & 1 & 1 & 1 \\
\hline \multirow{3}{*}{ RAF } & Wild-type & 25 & 19 & 44 \\
& Mutated & 2 & 1 & 3 \\
& Uninvestigated & 7 & 4 & 11 \\
\hline
\end{tabular}

patients receiving bevacizumab than for those given placebo $(\mathrm{p}=0.002)$. Regardless of the type of chemotherapy, patients treated with first-line chemotherapy plus bevacizumab consistently experience a median PFS interval in the range of 9-12 months and a median OS time of approximately 2 years. These results have been reached in several large trials, including CAIRO2, PACCE, HORIZON III trials $[38,39,40]$. Similar OS and PFS results were observed also in large observational studies, including BEAT, BRITE and ARIES trials [30,41,42]. In the ARIES study patients receiving FOLFOX plus bevacizumab in the first line had a median TTP and OS of 9.7 and 23.5 months, respectively [43] and patients receiving FOLFIRI plus bevacizumab had a median TTP and OS of 9.3 months and 26.3 months respectively.

Median TTP in our patients treated with the first-line chemotherapy in combination with bevacizumab was 8 months and was longer in patients treated with irinotecan-based regimens. Median OS achieved in our analysis 27 months. Our analysis included 58 patients, but achieved results are comparable to those presented in the larger studies mentioned above. This underlines the importance of monitoring and evaluation of treatment efficacy also in smaller groups of patients and these results can be used as a basis for larger pooled analyses. Approximately one quarter of CRC patients with distant metastases at initial diagnosis and one third of patients with mCRC have disease confined to the liver [44]. In these cases only radical surgery offers the chance of long-term survival. The safety and efficacy of bevacizumab in preoperative setting were evaluated in a post hoc analysis of the NO16966 and First BEAT clinical trials [45]. In the group of patients with metastases limited to the liver, $12.3 \%$ of patients treated with chemotherapy plus bevacizumab (26 of 211) eventually received a R0 resection, compared with $11.6 \%$ of patients (24 of 207) treated with chemotherapy plus placebo. Seven of 58 patients (12.07\%) in our analysis achieved operability following the first-line treatment with chemotherapy in combination with bevacizumab, 6 of them had metastases in the liver and 1 in lungs. Percentage of operability achieved in our study is comparable to the results of analysis mentioned above. Additional studies have assessed conversion therapy with bevacizumab in patients with liveronly metastases, with encouraging results $[46,47,48]$.

Most adverse events associated with bevacizumab are hypertension, proteinuria and bleeding, more serious are thromboembolic events, gastrointestinal perforations and wound-healing complications. In our analysis we evaluted the incidence of thromboembolic complications, which were observed in 10 patients (17.24\%). Deep thrombophlebitis occurred in 7 patients $(12.07 \%)$ and pulmonary embolism in 3 patients (5.17\%). On the other hand, arterial thromboembolism was not observed in our patients. Although AVF2107g study did not show an association between bevacizumab and the risk for venous thromboembolism (VTE), a metaanalysis of four placebo-controlled studies of chemotherapy with and without bevacizumab suggested a potential risk for VTE in patients receiving antiangiogenic therapy [49]. 
Another large pooled analysis of 10 placebo-controlled trials of chemotherapy with and without bevacizumab found no difference in the risk for VTE in patients receiving bevacizumab compared with placebo [50]. Therefore VTE still remains an important topic in all $\mathrm{mCRC}$ patients [51].

We separately evaluated the genetic profile of patients. Current consensus guidelines recommend that the presence of KRAS mutations has to be determined in all patients diagnosed with stage IV colorectal cancer. The KRAS mutation data were achievable for most of the patients included in our study. In addition, at our institute KRAS is now simultaneously analyzed together with $B R A F$, as the mutation detection system that had been introduced is enabling an easy and cost-effective parallel analysis of both genes. In our patients cohort only 3 of 47 patients analyzed displayed mutation V600E of BRAF, which represents $6.38 \%$, a frequency similar to those published elsewhere [18,19]. KRAS mutations were seen in 22 cases of 56 analyzed and also this frequency of KRAS changes in mCRC (39.29\%) is common. Our data basically support observations that KRAS status of colorectal cancer does not interfere with the efficacy of bevacizumab treatment [52]. In regard to mutations in BRAF gene, the positive patients occurred exclusively in the group of patients with progression and represented a very high percentage of the cases in this group $(42.8 \%)$. Our results indirectly support the notion that mutated $B R A F$ has a strong negative prognostic significance.

\section{References}

[1] O`CONNELL JB, MAGGARD MA, KO CY. Colon Cancer Survival Rates With the New American Joint Committee on Cancer Sixth Edition Staging. JNCI J Natl Cancer Inst 2004; 96(19): 1420-1425.

[2] JEMAL A, SIEGEL R, WARD E, HAO Y, XU J et al. Cancer statistics, 2008. CA Cancer J Clin 2008; 58(2): 71-96. http:// dx.doi.org/10.3322/CA.2007.0010

[3] SAVAS N, DAGLI U, AKBULUT S, YUKSEL O, SAHIN B. Colorectal cancer localization in young patients: should we expand the screening program? Dig Dis Sci. 2007 Mar; 52(3): 798-802. http://dx.doi.org/10.1007/s10620-006-9432-6

[4] VAN CUTSEM E, NORDLINGER B, CERVANTES A. Advanced colorectal cancer: ESMO Clinical Practice Guidelines for treatment. Ann Oncol 2010; 21(suppl 5): v93-v97. http:// dx.doi.org/10.1093/annonc/mdq222

[5] VAN CUTSEM E, NORDLINGER B, ADAM R, KOHNE $\mathrm{CH}, \mathrm{POZZO} \mathrm{C}$ et al. Towards a pan-European consensus on the treatment of patients with colorectal liver metastases. Eur J Cancer 2006; 42: 2212-2221. http://dx.doi.org/10.1016/ j.ejca.2006.04.012

[6] CHOTI MA, SITZMANN JV, TIBURI MF, SUMETCHOTIMETHA W, RANGSIN $\mathrm{R}$ et al. Trends in long-term survival following liver resection for hepatic colorectal metastases. Ann Surg 2002; 235(6): 759-66. http://dx.doi. org/10.1097/00000658-200206000-00002

[7] DE GRAMONT A, FIGER A, SEYMOUR M, HOMERIN M, HMISSI A et al. Leucovorin and fluorouracil with or without oxaliplatin as first-line treatment in advanced colorectal cancer. J Clin Oncol 2000; 18(16): 2938-47.

[8] DOUILLARD JY, CUNNINGHAM D, ROTH AD, NAVARRO $\mathrm{M}$, JAMES RD et al. Irinotecan combined with fluorouracil compared with fluorouracil alone as first-line treatment for metastatic colorectal cancer: a multicentre randomised trial. Lancet 2000; 355(9209): 1041-7. http://dx.doi.org/10.1016/ S0140-6736(00)02034-1

[9] SALTZ LB, COX JV, BLANKE C, ROSEN LS, FEHRENBACHER L et al. Irinotecan plus fluorouracil and leucovorin for metastatic colorectal cancer. Irinotecan Study Group. N Engl J Med 2000; 343(13): 905-14. http://dx.doi.org/10.1056/ NEJM200009283431302

[10] SARGENT DJ, CONLEY BA, ALLEGRA C, COLLETTE L. Clinical trial designs for predictive marker validation in cancer treatment trials. J Clin Oncol 2005; 23(9): 2020-2027. http://dx.doi.org/10.1200/JCO.2005.01.112

[11] VAN CUTSEM E, KOHNE CH, HITRE E, ZALUSKI J, CHANG CHIEN CR et al. Cetuximab and chemotherapy as initial treatment for metastatic colorectal cancer. N Engl J Med 2009; 360(14): 1408-1417. http://dx.doi.org/10.1056/ NEJMoa0805019

[12] LIEVRE A, BACHET JB, LE CORRE D, BOIGE V, LANDI B et al. KRAS mutation status is predictive of response to cetuximab therapy in colorectal cancer. Cancer Res 2006; 66(8): 3992-3995. http://dx.doi.org/10.1158/0008-5472.CAN-06-0191

[13] DE ROOCK W, PIESSEVAUX H, DE SCHUTTER J, JANSSENS M, DE HERTOGH G et al. KRAS wild-type state predicts survival and is associated to early radiological response in metastatic colorectal cancer treated with cetuximab. Ann Oncol 2008; 19(3): 508-515. http://dx.doi.org/10.1093/ annonc/mdm 496

[14] AMADO RG, WOLF M, PEETERS M, VAN CUTSEM E, SIENA $S$ et al. Wild-type KRAS is required for panitumumab efficacy in patients with metastatic colorectal cancer. J Clin Oncol 2008; 26(10): 1626-1634. http://dx.doi.org/10.1200/ LCO.2007.14.7116

[15] KARAPETIS CS, KHAMBATA-FORD S, JONKER DJ, O'CALLAGHAN CJ, TU D et al. K-ras mutations and benefit from cetuximab in advanced colorectal cancer. N Engl J Med 2008; 359(17): 1757-1765. http://dx.doi.org/10.1056/ NEJMoa0804385

[16] CIARDIELLO F, TORTORA G. EGFR antagonists in cancer treatment. N Engl J Med 2008; 358(11): 1160-1174. http:// dx.doi.org/10.1056/NEJMra0707704

[17] NORMANNO N, TEJPAR S, MORGILLO F, DE LUCA A, VAN CUTSEM E et al. Implications for KRAS status and EGFR-targeted therapies in metastatic CRC. Nat Rev Clin Oncol 2009; 6(9): 519-527. http://dx.doi.org/10.1038/ nrclinonc.2009.111

[18] VAN CUTSEM E, LANG I, FOLPRECHT G, NOWACKI M, CASCINU $S$ et al. Cetuximab plus FOLFIRI in the treatment of metastatic colorectal cancer (mCRC): The influence of KRAS and BRAF biomarkers on outcome: Updated data from the CRYSTAL trial. Gastrointestinal Cancers Symposium Orlando, 2010: 281.

[19] LOUPAKIS F, RUZZO A, CREMOLINI C, VINCENZI B, SALVATORE L et al. KRAS codon 61, 146 and BRAF muta- 
tions predict resistance to cetuximab plus irinotecan in KRAS codon 12 and 13 wild-type metastatic colorectal cancer. Br J Cancer 2009; 101(4): 715-721. http://dx.doi.org/10.1038/ sj.bjc. 6605177

[20] DI NICOLANTONIO F, MARTINI M, MOLINARI F, SARTORE-BIANCHI A, ARENA S et al. Wild-type BRAF is required for response to panitumumab or cetuximab in metastatic colorectal cancer. J Clin Oncol 2008; 26(35): 5705-5712. http://dx.doi.org/10.1200/JCO.2008.18.0786

[21] LAMBRECHTS D, DE ROOCK W, PRENEN H, DE SCHUTTER J, JACOBS B et al. The role of KRAS, BRAF, NRAS, and PIK3CA mutations as markers of resistance to cetuximab in chemorefractory metastatic colorectal cancer. J Clin Oncol 2009; 27: 4020.

[22] TEJPAR S, DE ROOCK W. PIK3CA, BRAF and KRAS mutations and outcome prediction in chemorefractory metastatic colorectal cancer (mCRC) patients treated with EGFR targeting monoclonal antibodies (MoAbs): results of a European Consortium. Eur J Cancer 2009; 7: 322. http://dx.doi. org/10.1016/S1359-6349(09)71100-0

[23] TOL J, NAGTEGAAL ID, PUNT CJ. BRAF mutation in metastatic colorectal carcinoma. N Engl J Med. 2009; 361: 98-99. http://dx.doi.org/10.1056/NEJMc0904160

[24] FERRARA N. Vascular endothelial growth factor. Arterioscler Thromb Vasc Biol. 2009; 29: 789-791. http://dx.doi. org/10.1161/ATVBAHA.108.179663

[25] SU X, LACOUTURE ME, JIA Y, WU S. Risk of high-grade skin rash in cancer patients treated with cetuximab - antibody against epidermal growth factor receptor: systemic review and metaanalysis. Oncology 2009; 77: 124-133. http://dx.doi. org $/ 10.1159 / 000229752$

[26] HURWITZ H, FEHRENBACHER L, NOVOTNY W, CARTWRIGHT T, HAINSWORTH J et al. Bevacizumab plus irinotecan, fluorouracil, and leucovorin for metastatic colorectal cancer. N Engl J Med 2004; 350: 2335-2342. http://dx.doi. org/10.1056/NEJMoa032691

[27] GIANTONIO BJ, CATALANO PJ, MEROPOL NJ, O'DWYER PJ, MITCHELL EP et al. Bevacizumab in combination with oxaliplatin, fluorouracil, and leucovorin (FOLFOX4) for previously treated metastatic colorectal cancer: results from the Eastern Cooperative Oncology Group Study E3200. J Clin Oncol 2007; 25: 1539-1544. http://dx.doi.org/10.1200/ LCO.2006.09.6305

[28] HOCHSTER HS, HART LL, RAMANATHAN RK, CHILDS BH, HAINSWORTH JD et al. Safety and efficacy of oxaliplatin and fluoropyrimidine regimens with or without bevacizumab as first-line treatment of metastatic colorectal cancer: results of the TREE Study. J Clin Oncol 2008; 26: 3523-3529. http:// dx.doi.org/10.1200/JCO.2007.15.4138

[29] HEDRICKE, KOZLOFF M, HAINSWORTHJ, BADARINATH S, COHN A et al. Safety of bevacizumab plus chemotherapy as first-line treatment of patients with metastatic colorectal cancer: updated results from a large observational registry in the US (BriTE). J Clin Oncol 2006; 24: 18s (Abstr 3536).

[30] VAN CUTSEM E, RIVERA F, BERRY S, KRETZSCHMAR A, MICHAEL M et al. Safety and efficacy of first-line bevacizumab with FOLFOX, XELOX, FOLFIRI and fluoropyrimidines in metastatic colorectal cancer: the BEAT study. Ann Oncol 2009; 20(11): 1842-1847. http://dx.doi.org/10.1093/annonc/mdp233

[31] KABBINAVAR FF, HAMBLETON J, MASS RD, HURWITZ HI, BERGSLAND E et al. Combined analysis of efficacy: the addition of bevacizumab to fluorouracil/leucovorin improves survival for patients with metastatic colorectal cancer. J Clin Oncol 2005; 23: 3706-3712. http://dx.doi.org/10.1200/ LCO.2005.00.232

[32] KABBINAVAR F, HURWITZ HI, FEHRENBACHER L, MEROPOL NJ, NOVOTNY WF et al. Phase II, randomized trial comparing bevacizumab plus fluorouracil (FU)/leucovorin (LV) with FU/LV alone in patients with metastatic colorectal cancer. J Clin Oncol 2003; 21: 60-65. http://dx.doi. org/10.1200/JCO.2003.10.066

[33] SALTZ LB, CLARKE S, DIAZ-RUBIO E, SCHEITHAUER W, FIGER A et al. Bevacizumab in combination with oxaliplatin-based chemotherapy as first-line therapy in metastatic colorectal cancer: a randomized phase III study. J Clin Oncol 2008; 26: 2013-2019. http://dx.doi.org/10.1200/ LCO.2007.14.9930

[34] HURWITZ H, SAINI S. Bevacizumab in the treatment of metastatic colorectal cancer: safety profile and management of adverse events. Semin Oncol 2006; 33(5 Suppl. 10): S26-S34. http://dx.doi.org/10.1053/j.seminoncol.2006.08.001

[35] EISENHAUER EA, THERASSE P, BOGAERTS J, SCHWARTZ LH, SARGENT D et al. New response evaluation criteria in solid tumours: Revised RECIST guideline (version 1.1) Eur J Cancer 2009; 45: 228-247. http://dx.doi.org/10.1016/ j.ejca.2008.10.026

[36] FUCHS CS, MARSHALL J, BARRUECO J. Randomized, controlled trial of irinotecan plus infusional, bolus, or oral fluoropyrimidines in first-line treatment of metastatic colorectal cancer: Updated results from the BICC-C study. J Clin Oncol 2008; 26: 689 - 690. http://dx.doi.org/10.1200/ JCO.2007.15.5390

[37] FUCHS CS, MARSHALL J, MITCHELL E, WIERZBICKI R, GANJU V et al. Randomized, controlled trial of irinotecan plus infusional, bolus, or oral fluoropyrimidines in first-line treatment of metastatic colorectal cancer: Results from the BICC-C study. J Clin Oncol 2007; 25: 4779-4786. http:// dx.doi.org/10.1200/JCO.2007.11.3357

[38] HECHT JR, MITCHELL E, CHIDIAC T, SCROGGIN C, HAGENSTAD $\mathrm{C}$ et al. A randomized phase IIIB trial of chemotherapy, bevacizumab, and panitumumab compared with chemotherapy and bevacizumab alone for metastatic colorectal cancer. J Clin Oncol 2009; 27: 672-680. http:// dx.doi.org/10.1200/JCO.2008.19.8135

[39] TOL J, KOOPMAN M, CATS A, RODENBURG CJ, CREEMERS GJ et al. Chemotherapy, bevacizumab, and cetuximab in metastatic colorectal cancer. N Engl J Med 2009; 360: 563-572. http://dx.doi.org/10.1056/NEJMoa0808268

[40] SCHMOLL H, CUNNINGHAM D, SOBRERO A, KARAPETIS C, ROUGIER P et al. mFOLFOX6 + cediranib vs mFOLFOX6 + bevacizumab in previously untreated metastatic colorectal cancer (mCRC): A randomized, double-blind, Phase II/III study (HORIZON III) [abstract 5800]. Ann Oncol 2010; 21(suppl 8): viii 189 
[41] KOZLOFF M, YOOD MU, BERLIN J, FLYNN PJ, KABBINAVAR FF et al. Clinical outcomes associated with bevacizumab-containing treatment of metastatic colorectal cancer: The BRiTE observational cohort study. The Oncologist 2009; 14: 862-870. http://dx.doi.org/10.1634/ theoncologist.2009-0071

[42] COHN AL, BEKAII-SAAB T, BENDELL JC, HURWITZ $\mathrm{H}$, KOZLOFF $\mathrm{M}$ et al. Clinical outcomes in bevacizumab (BV)-treated patients (pts) with metastatic colorectal cancer (mCRC): Results from ARIES observational cohort study (OCS) and confirmation of BRiTE data on BV beyond progression (BBP). J Clin Oncol 2010; 28(15 suppl): 3596.

[43] BENDELL JC, BEKAII-SAAB TS, COHN AL, HURWITZ $\mathrm{H}$, KOZLOFF $\mathrm{M}$ et al. Similarities in treatment $(\mathrm{Tx})$ patterns and clinical outcomes (CO) in patients (pts) with metastatic colorectal cancer (mCRC) initially treated with FOLFOX/BV or FOLFIRI/BV: Results from ARIES, a bevacizumab (BV) observational study. J Clin Oncol 2011; 29(4 suppl): 480.

[44] CHUA YJ, CUNNINGHAM D. Neoadjuvant treatment of unresectable liver metastases from colorectal cancer. Clin Colorectal Cancer 2006; 5: 405-412. http://dx.doi. org/10.3816/CCC.2006.n.011

[45] OKINES A, PUERTO OD, CUNNINGHAM D, CHAU I, VAN CUTSEM E et al. Surgery with curative-intent in patients treated with first-line chemotherapy plus bevacizumab for metastatic colorectal cancer First BEAT and the randomised phase-III NO16966 trial. Br J Cancer 2009; 101: 1033-1038. http://dx.doi.org/10.1038/sj.bjc.6605259

[46] BERTOLINI F, MALAVASI N, SCARABELLI L, FIOCCHI F, BAGNI B et al. FOLFOX6 and bevacizumab in non-optimally resectable liver metastases from colorectal cancer. Br J Cancer 2011; 104: 1079 -1084. http://dx.doi.org/10.1038/ bjc. 2011.43
[47] WONG R, SAFFERY C, BARBACHANO Y, CHAU I, VALLE $J$ et al. BOXER: A multicentre phase II trial of capecitabine and oxaliplatin plus bevacizumab as neoadjuvant treatment for patients with liver-only metastases from colorectal cancer unsuitable for upfront resection. Eur J Cancer 2009; 7: 344-345. http://dx.doi.org/10.1016/S1359-6349(09)71171-1

[48] RIBERO D, WANG H, DONADON M, ZORZI D, THOMAS $\mathrm{MB}$ et al. Bevacizumab improves pathologic response and protects against hepatic injury in patients treated with oxaliplatin-based chemotherapy for colorectal liver metastases. Cancer 2007; 110: 2761-2767. http://dx.doi.org/10.1002/ cncr.23099

[49] NALLURI SR, CHU D, KERESZTES R, ZHU X, WU S et al. Risk of venous thromboembolism with the angiogenesis inhibitor bevacizumab in cancer patients: A meta-analysis. JAMA 2008; 300: 2277-2285. http://dx.doi.org/10.1001/ jama.2008.656

[50] CASSIDY J, SALTZ L, VAN CUTSEM E, HEDRICK EE, LASSERRE $S$ et al. Venous thromboembolic events with chemotherapy plus bevacizumab: A pooled analysis of over 6, 000 patients in randomized phase II and III studies. J Clin Oncol 2010; 28(15 suppl): 3604.

[51] ALCALAY A, WUN T, KHATRI V, CHEW HK, HARVEY D et al. Venous thromboembolism in patients with colorectal cancer: Incidence and effect on survival. J Clin Oncol 2006; 24: 1112-1118. http://dx.doi.org/10.1200/JCO.2005.04.2150

[52] HURWITZ HI, YI J, INCE W, NOVOTNY WF, ROSEN O. The Clinical Benefit of Bevacizumab in Metastatic Colorectal Cancer Is Independent of K-ras Mutation Status: Analysis of a Phase III Study of Bevacizumab with Chemotherapy in Previously Untreated Metastatic Colorectal Cancer. The Oncologist 2009; 14(1): 22-8. http://dx.doi.org/10.1634/ theoncologist.2008-0213 